\title{
Thermomechanical Behaviour of Monocrystalline Cu-Al-Be Shape Memory Alloys and Determination of the Metastable Phase Diagram
}

\author{
A. Hautcoeur, A. Eberhardt*, E. Patoor* and M. Berveiller* \\ IMAGO S.A., ZI Athélia I, Bât. Delta, 13600 La Ciotat, France \\ * Laboratoire de Physique et Mécanique des Matériaux, Institut Supérieur de Génie Mécanique et Producti- \\ que, Ile du Saulcy, 57045 Metz cedex 1, France
}

\begin{abstract}
Stress-strain behaviour of monocrystalline $\mathrm{Cu}-\mathrm{Al}-\mathrm{Be}$ alloy was investigated by uniaxial tensile tests in a temperature range between $-70^{\circ} \mathrm{C}$ and $+160^{\circ} \mathrm{C}$. Four kinds of typical behaviours were examined in this study.

Main interest was the determination of the $\sigma$-T diagram obtained from the $\sigma$ - $\varepsilon$ curves. This metastable phase diagram is comparable to the $\mathrm{Cu}-\mathrm{Al}-\mathrm{Ni}$ one.

Isothermal mechanical cycling was made at $6 \%$ strain up to 1500 cycles. As a result, a deterioration of the superelastic behaviour was found. A thermal flash allows to partially recover this behaviour.

Rupture tests performed at a temperature above $120^{\circ} \mathrm{C}$ have shown the critical stress above which either brittle fracture of $\alpha$ ' martensite occurs or plastic deformation of $\beta$ phase takes place.

Finally, comparative tests have been made between a single crystal, a polycrystal with small grains and a polycrystal with columnar structure (bamboo-type).
\end{abstract}

\section{INTRODUCTION}

The thermomechanical characterization of $\mathrm{Cu}-\mathrm{Al}$ - $\mathrm{Be}$ alloy single crystals has been carried out from tensile tests at different temperatures. From these tests, we deduce the metastable phase diagram $\sigma$ - $T$ which is an important data for the use of Shape Memory Alloys. The diagram shows the stability areas of the different martensitic phases.

Fatigue and fracture strength are also two important criterias for the use of a shape memory alloy. So, isothermal fatigue tests on single crystals shows the evolution of $\sigma-\varepsilon$ curves as a function of the number of cycles. The relatively fast degradation of the superelastic properties is due to a microstructure modification that can be partially regenerated with a thermal flash.

On the other hand, fracture tests have allowed to distinguish two behaviours :

- brittleness of the $\alpha^{\prime}$ martensite at low and intermediate temperature $\left(\mathrm{T}<150^{\circ} \mathrm{C}\right)$,

- ductility of the $\beta$ phase (and eventually $\left.\alpha^{\prime}\right)$ at high temperature $\left(\mathrm{T}>250^{\circ} \mathrm{C}\right)$.

Finally, we compare the behaviour of a single crystal, a columnar structure specimen (bamboo-type) and a polycristal with small grain size. The interest of this experiment is based on the fact that the single crystal and bamboo-type specimens have absolutly the same composition. The polycristal has a slightly different composition but the difference between temperature test and $\mathrm{M}_{\mathrm{S}}$ is quite similar.

\section{EXPERIMENTAL PROCEDURE}

A Cu-11.6Al-0.52Be (weight\%) alloy polycrystal has been transformed into single crystals $(\varnothing 4.5 \mathrm{~mm}$ and $\emptyset 1.6 \mathrm{~mm}$ ) by a modified Bridgman method. No heat treatment has been made after elaboration. The 
orientation is always close to [001] and the orientation factor is in the range between 0.47 and 0.49 (Schmid factor).The tensile tests have been done by using a Zwick machine with an chamber allowing to reach temperatures in the range between -70 and $+190^{\circ} \mathrm{C}$. In all the range of temperature, the measure of strain is made with an extensometer. A temperature sensor is placed on the specimen to know the temperature of the material during the test. The strain rate is about $1.510^{-3} / \mathrm{s}$. Each test is preceded by a thermal flash at $200^{\circ} \mathrm{C}$ to remove any possible stabilized martensite.

\section{EXPERIMENTAL RESULTS AND DISCUSSION}

\section{1. $\sigma-\varepsilon$ curves and $\sigma-T$ diagram}

The metastable phase $\sigma-\mathrm{T}$ diagram has been already determined by tensile tests for the $\mathrm{Cu}-\mathrm{Al}-\mathrm{Ni}{ }^{[1][2]}$ and $\mathrm{Cu}-\mathrm{Zn}-\mathrm{Al}^{[3]}$ alloys. The critical stresses of the different martensitic transformations are determy from the $\sigma$ - $\varepsilon$ curves. The $\sigma$-T diagram of the Cu-Al-Ni alloy shows four types of martensite : $\gamma^{\prime}, \beta^{\prime}, \beta^{\prime \prime} e$ The $\beta$ ' phase forms from the austenite $\beta$ and the $\beta$ " phase from the $\gamma$ ' martensite. 1

Similars $\sigma-\varepsilon$ curves and $\sigma$-T diagram have been drawn for CuAlBe alloy by using a specimen with $a_{c}^{e}$ meter of $1.6 \mathrm{~mm}(\mathrm{MO} 25)\left(\mathrm{Ms}=-10^{\circ} \mathrm{C}\right)$ (figure 1). The main types of $\sigma-\varepsilon$ curves for different temperat $\mathrm{h}_{\mathrm{h}}$ are represented figure 2 .

The diagram shows four characteristics temperatures :

- $\mathrm{M}_{\mathrm{s}}$ corresponds to the beginning of the austenite-martensite transformation,

- $A_{f}$ corresponds to the end of the martensite-austenite transformation,

$-\mathrm{Tc}_{\mathrm{i}}$ is the critical temperature when the reverse $\alpha^{\prime} \rightarrow \beta^{\prime}$ and $\beta^{\prime} \rightarrow \beta$ transformations simultaneously take place,

$-\mathrm{T}_{\mathrm{d}}$ is the critical temperature from which the direct $\beta^{\prime} \rightarrow \beta$ and $\beta^{\prime} \rightarrow \alpha^{\prime}$ transformations simultaneously take place.

\subsubsection{Thermomechanical behaviour in a temperature range below $M_{S}$}

The curve $a$ (figure 2 ) corresponding to a test temperature $\mathrm{T}=-51^{\circ} \mathrm{C}$ shows at the start of loading the reorientation of the thermally formed martensites $\gamma^{\prime}$ and/or $\beta$ '. A slope change appears at $130 \mathrm{MPa}$ followed by a stage around $190 \mathrm{MPa}$. The part of the curve between 130 and $190 \mathrm{MPa}$ can be attributed to a phase transformation stress. The slope preceding the plateau should correspond to the end of the reorientation associated to the phase transformation and the plateau to the end of this transformation. This stage is followed by a quite important slope and a "hump" which peak reaches $320 \mathrm{MPa}$. After this hump, an another stage appears at a slightly lower stress. This plateau represent the $\beta^{\prime \prime} \rightarrow \alpha^{\prime}$ transformation. The reverse $\alpha^{\prime} \rightarrow \beta^{\prime}$ transformation shows a low stress at unloading. The important residual deformation is nearing $10 \%$.

This type of behaviour has already been mentioned for a Cu-14.1A1 ${ }^{[4][5]}$. Gyobu et al. ${ }^{[5]}$ explained that the hump appears only when the low temperature martensite structure is $2 \mathrm{H}\left(\gamma^{\prime}\right)$ or $2 \mathrm{H}+18 \mathrm{R}\left(\gamma^{\prime}+\beta^{\prime}\right)$. It does not appear when only $18 \mathrm{R}$-martensite $\left(\beta^{\prime}\right)$ exist. According to the reports by Sakamoto, in CuAlNi alloys with low $\mathrm{Ni}$ content, the critical stress of the $\beta$ " $\rightarrow \alpha$ ' transformation should be lower than the one of the $\gamma \rightarrow \beta$ " transformation. This explains that the specimen must reach a higher stress to transform in $\beta$ " before the martensite $\alpha^{\prime}$ appears. The small stage at $190 \mathrm{MPa}$ can be attributed to the transformation of a small fraction of stabilized martensite $\gamma^{\prime}$ into $\beta^{\prime \prime}$ such as it has been already observed in some Cu-Al-Ni alloys ${ }^{[6]}$. In any case, the thermomechanical behaviour of the $\mathrm{Cu}-\mathrm{Al}-\mathrm{Be}$ alloy in a temperature below $\mathrm{M}_{\mathrm{s}}$ extremely depends on the presence or not of either of the two martensites $\gamma^{\prime}$ and $\beta^{\prime}$. The composition and cooling mode after heat treatment or elaboration are also important factors, such as in the case of $\mathrm{Cu}-\mathrm{Al}-\mathrm{Ni}$ alloys $[4][6][7][8]$.

In the $\sigma-\mathrm{T}$ diagram (figure 1 ), the two hypothesis $\beta$ " $\rightarrow \gamma^{\prime}$ transformation are represented with dotted lines. The $\beta^{\prime} \leftrightarrow \alpha^{\prime}$ transformation hysteresis reaches about 270 to $280 \mathrm{MPa}$.

\subsubsection{Thermomechanical behaviour in the temperature range between $M_{s}$ and $T_{d}$}

The temperature range between $M_{S}$ and $A_{f}(b)$ corresponds to the incomplete $\beta \leftrightarrow \beta$ ' transformation. So, the reverse $\beta^{\prime} \rightarrow \beta$ transformation stage does not appears. 


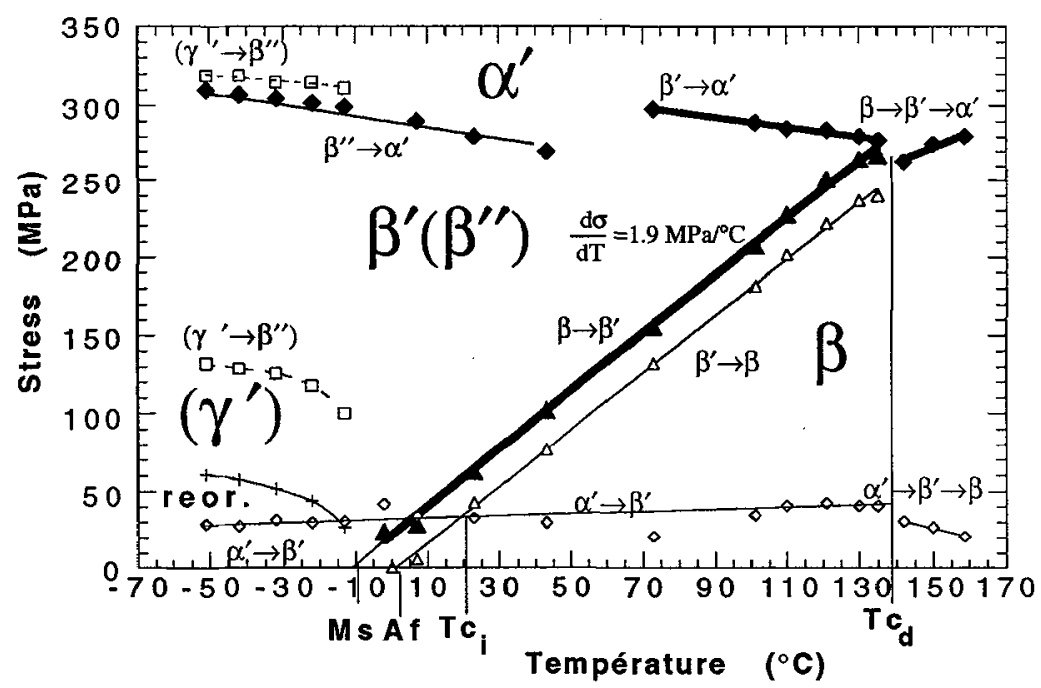

Figure 1 : $\sigma$-T phase diagram of the MO25 specimen.
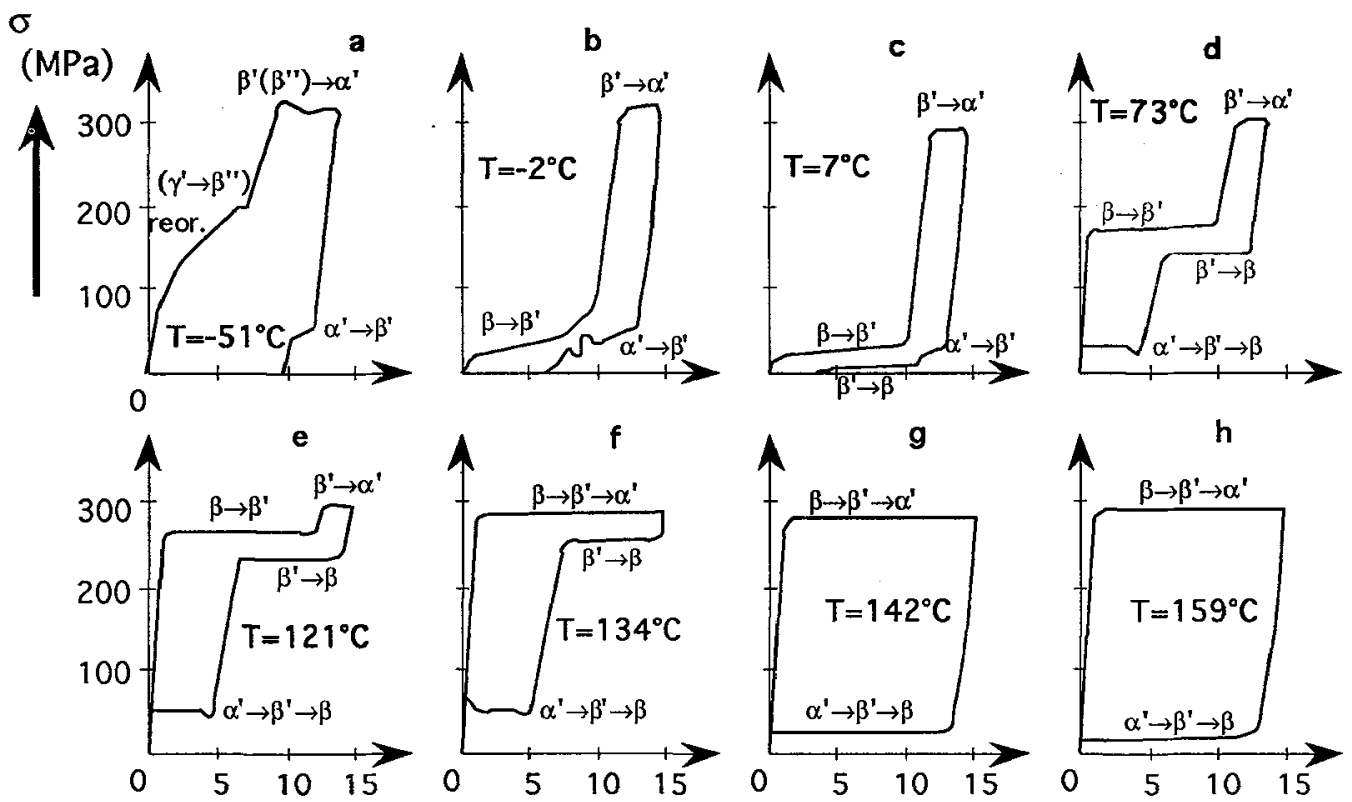

(\%)

Figure 2 : Stress-strain curves of the MO25 specimen (CuAlBe) as a function of the temperature. 
In a temperature range between $A_{\mathrm{f}}$ and $\mathrm{Tc}_{\mathrm{i}}(c)$, the first two stages in the $\sigma-\varepsilon$ curve corresponds respectively to the $\beta \rightarrow \beta^{\prime}$ and $\beta^{\prime} \rightarrow \alpha^{\prime}$ transformations. The critical stresses of the $\beta \rightarrow \beta^{\prime}$ and $\beta^{\prime} \rightarrow \beta$ transformations increases with increasing temperature with a slope $d \sigma / \mathrm{dT}=1.9 \mathrm{MPa} /{ }^{\circ} \mathrm{C}$. The hysteresis of this transformation is about $25 \mathrm{MPa}$. The reverse $\beta \rightarrow \beta$ transformation is only observed in the temperature range above $A_{f}$ $\left(b\right.$ and $c$ ). The hysteresis of the $\beta^{\prime}\left(\beta^{\prime \prime}\right) \leftrightarrow \alpha^{\prime}$ transformation is more important (180 à $\left.220 \mathrm{MPa}\right)$. The critical stresses of the $\alpha^{\prime} \rightarrow \beta^{\prime}$ transformation decreases with a slope $\mathrm{d} \sigma / \mathrm{dT}=-0.3 \mathrm{MPa} /{ }^{\circ} \mathrm{C}$. The direct $\beta^{\prime \prime} \rightarrow \alpha^{\prime}$ transformation shows a discontinuity around $50^{\circ} \mathrm{C}$. Some $\mathrm{Cu}-\mathrm{Al}-\mathrm{Ni}$ alloys composition also present a discontinuity for this type of transformation. Sakamoto attributes the $\beta$ ' $\rightarrow \alpha$ ' transformation to the left part of the curve and the $\beta^{\prime} \rightarrow \alpha^{\prime}$ to the right part.

Regarding to the reversion of the $\alpha^{\prime}$ phase, in a temperature range between $\mathbf{M}_{\mathrm{S}}$ and $\mathrm{Tc}_{\mathrm{i}}(b$ and $c)$, the $\alpha^{\prime}$ martensite formed from $\beta^{\prime}$ on loading, first reverse on unloading. On the other hand, above $\mathrm{Tc}_{\mathrm{i}}(d$ and $e)$, the critical stress of reversion of martensite $\alpha^{\prime}$ being lower than those of the reversion of the martensite $\beta^{\prime}$, the both transformations $\beta^{\prime} \rightarrow \beta$ et $\alpha^{\prime} \rightarrow \beta^{\prime}$ occur simultaneously at the lowest stress. The stage $\beta^{\prime} \rightarrow \beta$ in figure $e$ corresponds to a fraction of the specimen that is not transformed into $\alpha$ '.

\subsubsection{Thermomechanical behaviour in a temperature range above $T c_{d}$}

In a temperature range above $\mathrm{Tc}_{d}(f$ to $h)$, the both transformations $\beta \rightarrow \beta^{\prime}$ et $\beta^{\prime} \rightarrow \alpha^{\prime}$ occur simultaneously and the critical stress increases with increasing temperature. The both reverse transformations $\alpha^{\prime} \rightarrow \beta^{\prime}$ and $\beta^{\prime} \rightarrow \beta$ also occur at the same stress but this stress decreases with increasing temperature. At $150^{\circ} \mathrm{C}$, this critical stress is lower than $0 \mathrm{MPa}$ and the formed $\alpha^{\prime}+\beta^{\prime}$ martensite is still stabilized. A thermal flash at $200^{\circ} \mathrm{C}$

on the stress free specimen allows to recover the total residual strain.

\subsection{Isothermal mechanical cycling}

A $\varnothing 4.5 \mathrm{~mm} \mathrm{Cu}-\mathrm{Al}-\mathrm{Be}$ single crystal was grown by a modified Bridgman method. Fatigue tests were carried out up to $6 \%$ strain and at a temperature $\mathrm{T}=55^{\circ} \mathrm{C}$. Figure 3 shows the evolution of the $\sigma-\varepsilon$ curves after 500 and 1500 cycles ( $b$ and $c$ ). However, a thermal flash at $200^{\circ} \mathrm{C}$ allows to quite entirely recover the initial behaviour of the alloy $(d)$.

The evolution of $\sigma$ - $\varepsilon$ curves as a function of the number of cycles has been already observed with the $\mathrm{Cu}-\mathrm{Zn}-\mathrm{Al}{ }^{[9][10]}$ and $\mathrm{Cu}-\mathrm{Al}-\mathrm{Ni}^{[11]}$ alloys. The deterioration of the superelastic behaviour is attributed to the formation of surface and volume defects ${ }^{[10]}$. These defects (dislocations) can be partially restored by heating up $200^{\circ} \mathrm{C}$ as shown in figure $d$. However,

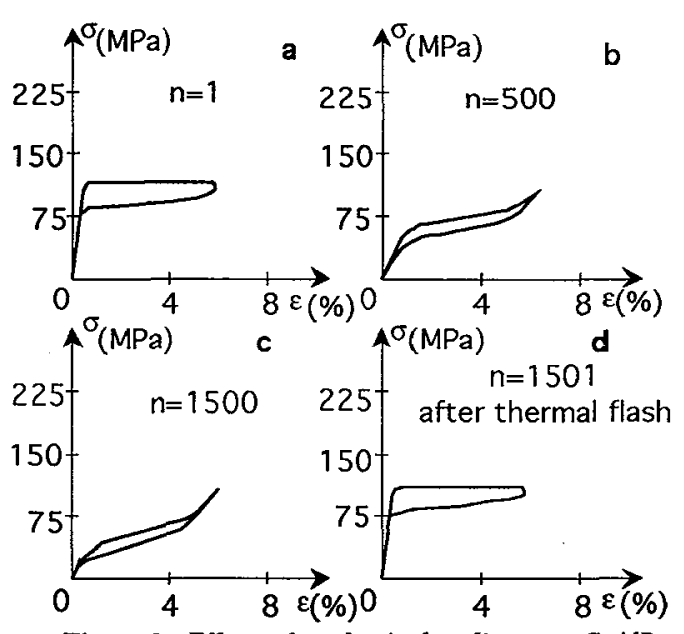

Figure 3 : Effects of mechanical cycling on a CuAlBe single crystal $\left(T=55^{\circ} \mathrm{C}\right.$, . a new cycling leads to a quicker deterioration of the superelastic phenomenon.

\subsection{Fracture limit. High temperature plasticity limit}

At a temperature below $-20^{\circ} \mathrm{C}$, the material is in martensite and the fracture takes place between 300 and $400 \mathrm{MPa}$ sometimes before the $\beta^{\prime}\left(\beta^{\prime \prime}\right) \rightarrow \alpha^{\prime}$ transformation began (figure $4 a$ and $b$ ). Above $\mathrm{M}_{\mathrm{s}}$, the fragile fracture of $\alpha^{\prime}$ occurs up to $500 \mathrm{MPa}(c)$.

At temperatures above $250^{\circ} \mathrm{C}$, the fracture becomes ductile and happens probably in front of austenite and eventually $\beta^{\prime}$ and/or $\alpha^{\prime}$ martensite. Two specimens were tensile tested at 256 and $260^{\circ} \mathrm{C}$ (a single crystal $(f)$ and a polycrystal $(d)$ ) and a third one at $320^{\circ} \mathrm{C}$ (polycrystal $(e)$ ). In the three cases, the elastic slope of the austenite is followed by a plastic flow and the appearance of a striction leading to the fracture. The stress of plasticity $\sigma_{\mathrm{p}}$ for the single crystal at $256^{\circ} \mathrm{C}\left(\sigma_{\mathrm{p}}=326 \mathrm{MPa}\right)$ is lower than the one of the polycrystal 
at $260^{\circ} \mathrm{C}\left(\sigma_{\mathrm{p}}=572 \mathrm{MPa}\right)$. At $320^{\circ} \mathrm{C}, \sigma_{\mathrm{p}}$ goes down to $228 \mathrm{MPa}$ for the polycristal.

\subsection{Comparison single crystal-polycrystal}

Figure 5 illustrates the tensile behaviour for three $\mathrm{Cu}-\mathrm{Al}-\mathrm{Be}$ specimens. Two specimens $a$ et $b$ were grown by the Bridgman method. Their composition is identical and the $\mathrm{M}_{\mathrm{s}}$ temperature is nearby $0^{\circ} \mathrm{C}$. The specimen $a$ is monocrystalline, the specimen $b$ shows a bamboo-type structure (grain size : $\mathrm{d} \sim 1 \mathrm{~mm}$ ). The specimen $c$ is polycrystalline with $\mathrm{M}_{\mathrm{S}}=-30^{\circ} \mathrm{C}$ (grain size : $\mathrm{d}=0.079 \mathrm{~mm}$ ). $a$ and $\mathrm{b}$ were tested at $25^{\circ} \mathrm{C}$ and $c$ at $0^{\circ} \mathrm{C}$, so that the difference between the test temperature and the $M_{s}$ temperature remains the same for the three specimens.

The critical stress of the polycristal $\left(\sigma_{\mathrm{c}}=121 \mathrm{MPa}\right)$ is clearly more important than the one of the single crystal or of the specimen with a bamboo-type structure $\left(\sigma_{c}\right.$ mono $=\sigma_{\mathrm{c} \text { bamboo }}=43 \mathrm{MPa}$ ). The Hall-Petch law establishing that the critical stress decrease with increasing the grain size has been verified for polycrystals ${ }^{[12]}$. It is confirmed by the present curves. The critical stresses of $a$ and $b$ are equal. In a polycrystal, the largest well-oriented grains transform first. In a bamboo-type specimen, the largest grains which transform first, have the same dimensions and the same orientation
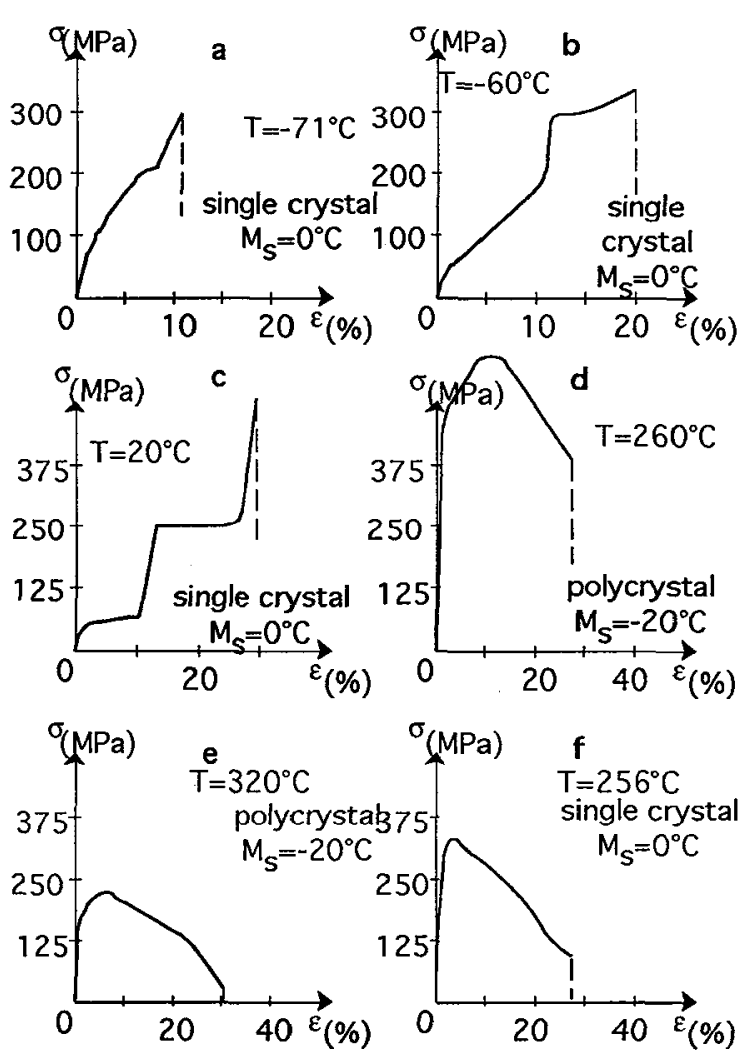

Figure 4 : Fracture strength of CuAlBe single- and polycrystals at different temperatures.

When the strain increases, the transformation stress of bamboo-type specimen increases, even though the transformation stress of the single crystal is still the same. At $8 \%$ strain, the stress reaches $250 \mathrm{MPa}$ for the bamboo-type. For the polycrystal, the evolution is identical but the stresse is higher ( $\sigma=465 \mathrm{MPa})$. The residual strain also changes a lot with the type of specimen. $\varepsilon_{\mathrm{r}}=0 \%$ for the single crystal, $\varepsilon_{\mathrm{r}}=1.5 \%$ for the bamboo-type and $\varepsilon_{\mathrm{T}}=4.6 \%$ for the polycrystal.
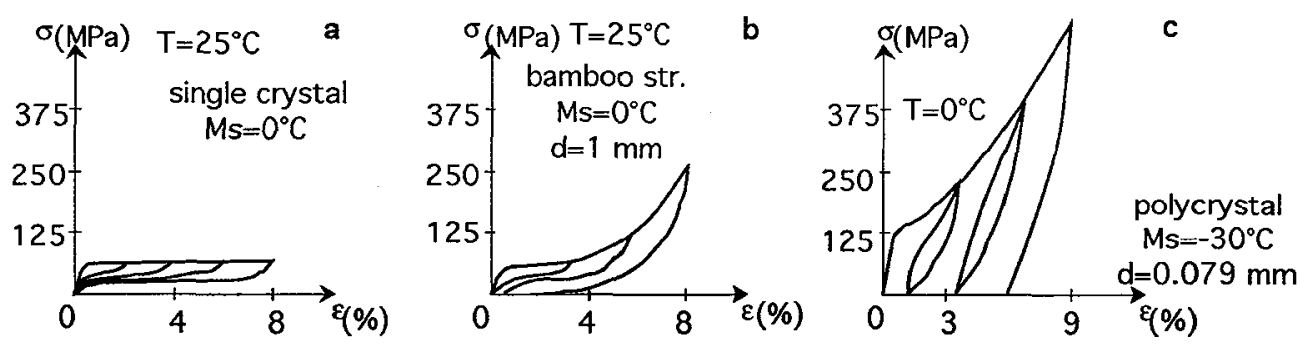

Figure 5 : Comparison of the tensile behaviour of a single crystal, a bamboo-type specimen and a polycristal with small grains (CuAlBe). 


\section{CONCLUSION}

The thermomechanical behaviour of $\mathrm{Cu}-\mathrm{Al}-\mathrm{Be}$ alloy has been investigated by using single crystals with nearly [001] orientation. The followings have been clarified from the investigation.

1- The stress-strain behaviour of $\mathrm{Cu}-\mathrm{Al}-\mathrm{Be}$ alloy single crystal is analogous to the $\mathrm{Cu}-\mathrm{Al}-\mathrm{Ni}$ one.

2- Below $M_{s}$, the reorientation of $\beta^{\prime}$ and/or $\gamma^{\prime}$ phases is eventually followed by the $\gamma^{\prime} \rightarrow \beta^{\prime \prime}$ transformation and then by the $\beta^{\prime \prime} \rightarrow \alpha$ ' transformation.

3- Above $M_{s}$, the $\beta \rightarrow \beta^{\prime}$ and $\beta^{\prime} \rightarrow \alpha^{\prime}$ transformations successively take place and then simultaneously occur above $T c_{\mathrm{d}}$.

4- Isothermal mechanical cycling induces accumulation of defects partially reversible by heating at $200^{\circ} \mathrm{C}$.

5- Fragile fracture of $\alpha^{\prime}$ phase happens above $500 \mathrm{MPa}$ and ductile fracture of the austenite at high temperature (with eventually $\alpha$ ' martensite) occurs after striction of the specimen.

6- The critical stress of a polycrystal decreases with increases grain size. It is minimal for a single crystal (infinite grain size). The residual strain of the polycrystal is higher than the bamboo-type specimen one. The residual strain of the single crystal for a same imposed deformation is null.

\section{REFERENCES}

(1) K. Otsuka, H. Sakamoto, K. Shimizu, Acta Met., 27 (1979) 585.

(2) H. Sakamoto, K. Shimizu, K. Otsuka, Trans. Jpn. Inst. Met., 26 (1985) 638.

(3) T. Saburi, Y. Inada, S. Nenno, N. Hori, Proc. Intern. Conf. on Martensitic Transformations, Leuven, J. de Phys., Colloq. 43 (1982) C4-633.

(4) H. Sakamoto, M. Yoshikawa, K. Shimizu, Mat. Transactions, JIM, 31 (1990) 848.

(5) A. Gyobu, K. Enami, A. Nagasawa, S. Nenno, Proc. Intern. Conf. on Martensitic Transformations, Leuven, J. de Phys., Colloq. 43 (1982) C4-641.

(6) H. Sakamoto, K. Shimizu, ISIJ International, 29 (1989) 395.

(7) H. Sakamoto, Y. Nakai, K. Shimizu, Trans. Jpn. Inst. Met., 28 (1987) 765.

(8) H. Sakamoto, Y. Nakai, K. Shimizu, Trans. Jpn. Inst. Met., 28 (1987) 264.

(9) M. Sade, R. Rapacioli, M. Alhers, Acta Met., 33 (1985) N³ 487.

(10) E. Hornbogen, in : "Engineering Aspects of Shape Memory Alloys", T.W. Duerig, K.N. Melton,

D.Stöckel, C.M. Wayman, (Ed. Butterworth-Heinemann) pp. 267-280.

(11) H. Sakamoto, Trans. Jpn. Inst. Met., 24 (1983) 665.

(12) P. Barbe, Doctorat thesis, (1994), to be published. 